\title{
Photocatalytic oxidation of Reactive Black 5 with UV-A LEDs
}

\author{
Leonor C. Ferreira ${ }^{a}$, Marco S. Lucas ${ }^{a, b, *}$, José R. Fernandes ${ }^{c, d}$, Pedro B. Tavares ${ }^{a}$ \\ a Centro de Química-Vila Real, Departamento de Química, UTAD-Universidade de Trás-os-Montes e Alto Douro, Quinta de Prados, 5000-801 Vila Real, \\ Portugal \\ ${ }^{\mathbf{b}}$ Environmental Nanocatalysis \& Photoreaction Engineering, Chemical Engineering Department, Loughborough University, Loughborough LE11 3TU, United \\ Kingdom \\ ${ }^{\mathrm{c}}$ Departamento de Física, UTAD-Universidade de Trás-os-Montes e Alto Douro, Quinta de Prados, 5000-801 Vila Real, Portugal \\ ' INESC-TEC, Rua do Campo Alegre, 687, 4169-007 Porto, Portugal
}

\section{A R T I C L E I N F O}

\section{Article history:}

Received 23 March 2015

Received in revised form 29 October 2015

Accepted 30 October 2015

Available online 4 November 2015

\section{Keywords:}

Heterogeneous photocatalysis

Titanium dioxide

Light emitting diodes

Reactive Black 5

UV-A

\begin{abstract}
A B S T R A C T
The effectiveness of UV-A Light emitting diodes (UV-A LEDs) for decolourization of Reactive Black 5 (RB5) solutions in a continuous photoreactor and the effect of different operational parameters on the photocatalytic decolourization of RB5 were investigated in the present work. The operational parameters included catalyst load, initial dye concentration, irradiance and solution flowrate. Photocatalytic experiments were conducted in a self-designed photoreactor with a matrix of 96 UV-A LEDs $(375 \mathrm{~nm})$ and Evonik $\mathrm{P}-25 \mathrm{TiO}_{2}$ was used as a photocatalyst. The optimum experimental conditions that allowed the highest decolourization of RB5 (89\%) were an irradiance of $40 \mathrm{~W} / \mathrm{m}^{2}, 1.0 \mathrm{~g} / \mathrm{L}$ of $\mathrm{TiO}_{2}, 50 \mathrm{mg} / \mathrm{L}$ of RB5 and a flowrate of $0.8 \mathrm{~mL} / \mathrm{min}$.

A continuous stirred tank reactor (CSTR) design equation, subsequently simplified to a pseudo-first order rate equation, was used to analyse the kinetics of the experimental results. From the kinetics it is possible to observe that high $\mathrm{TiO}_{2}$ concentrations $(1.0 \mathrm{~g} / \mathrm{L})$ and light irradiances $\left(40 \mathrm{~W} / \mathrm{m}^{2}\right)$ positively affect the reaction rate $\left(r, 2.483 \times 10^{-7} \mathrm{~mol} / \mathrm{L} \mathrm{min}\right)$ and the reaction rate constants $\left(k, 7.351 \times 10^{-3} \mathrm{~min}^{-1}\right)$.

The figure-of-merit electrical energy per order $\left(E_{\mathrm{EO}}\right)$ was calculated for the photoreactor, and values of $220 \mathrm{kWh} / \mathrm{m}^{3} /$ order were reached for an electric power consumption of $0.0129 \mathrm{~kW}$ and a solution flowrate of $4.8 \times 10^{-6} \mathrm{~m}^{3} / \mathrm{h}$. Results demonstrated that a UV-A LED $/ \mathrm{TiO}_{2}$ process can effectively decolourize RB5 dye solutions within the selected optimum conditions.
\end{abstract}

(c) 2015 Elsevier Ltd. All rights reserved.

\section{Introduction}

The textile industry is one of the largest polluters worldwide. The industry has a high water consumption and uses an elevated number of compounds, of which dyes and pigments are the most problematic. This results in a large volume of highly toxic and barely biodegradable wastewater [1,2].

The removal of toxic and/or refractory contaminants from water using conventional treatments (e.g. coagulation/flocculation, biological treatment) is difficult and finding new and effective wastewater treatment processes to restore water quality is a major challenge.

\footnotetext{
* Corresponding author at: Environmental Nanocatalysis \& Photoreaction Engineering, Chemical Engineering Department, Loughborough University, Loughborough LE11 3TU, United Kingdom.

E-mail addresses: mlucas@utad.pt, m.p.lucas@lboro.ac.uk (M.S. Lucas).
}

In this context, Advanced Oxidation Processes (AOPs) have emerged as a suitable route for mineralization of organic contaminants in water and wastewater $[3,4]$. Of these, photocatalysis stands out as the most environmentally friendly, with a wide application in the total degradation of organic contaminants into $\mathrm{H}_{2} \mathrm{O}$ and $\mathrm{CO}_{2}[5,6]$.

Furthermore, titanium dioxide $\left(\mathrm{TiO}_{2}\right)$ is the most applied photocatalyst in wastewater treatment, since it is inexpensive, chemically stable and its photogenerated holes and electrons are highly oxidizing and reducing, respectively $[7,8]$. However, due to its large band gap (3.2 eV for anatase), which prevents the use of visible light in photocatalytic reactions, it can only be activated by UV radiation [9]. Currently, conventional UV-driven applications are based on low or medium pressure mercury vapour lamps. However, several drawbacks are associated with these lamps. They include instability upon long-term exposure due to overheating, low photonic efficiency resulting in high energy consumption, short lifetime, and, since mercury is a hazardous pollutant, issues 
related to end of life disposal [10,11]. Therefore, a search for alternative, cost-effective and efficient UV radiation sources has been pursued.

Recent advances on the development of light emitting diodes (LEDs) have opened the possibility of employing LEDs as an alternative artificial UV radiation source for photoreactors [12-14]. Potential advantages over traditional UV lamps offered by LEDs include greater efficiency in converting electricity into light (high quantum yields), lower power requirements, compactness and robustness, no warm-up time, potential for long lifetimes, the enabling of the construction of reactors with variable geometries and the avoiding of the use of environmentally hazardous heavy metals (such as mercury) [11,15,16]. Among UV LEDs, several options, which impact on UV-driven efficiency and treatment costs, are available (e.g. different peak emission wavelength, output optical power). Exploring the substitution of common UV lamps with low-cost UV-A LEDs, this work aims to present a lowcost alternative to conventional UV-driven treatment processes.

The objective of this study was to determine the efficiency of currently marketed UV-A LEDs in the photocatalytic degradation of a textile azo dye (Reactive Black 5) in continuous flow through mode. The effect of various parameters such as catalyst loading, initial dye concentration, UV-LEDs irradiance $\left(\mathrm{W} / \mathrm{m}^{2}\right)$ and dye solution flowrate were investigated. For the first time, UV-A LEDs were used in photocatalytic wastewater treatment using Reactive Black 5 as a key organic pollutant.

\section{Materials and methods}

\subsection{Reagents}

The azo dye, Reactive Black $5\left(\mathrm{C}_{26} \mathrm{H}_{21} \mathrm{~N}_{5} \mathrm{O}_{19} \mathrm{~S}_{6} \mathrm{Na}_{4}\right.$, CI 20505), was kindly provided by DyStar (Portugal) and used as received. UV-vis absorption spectra of Reactive Black 5 in non-hydrolyzed form is illustrated in Fig. S1. Titanium dioxide $\left(\mathrm{TiO}_{2}\right.$, P25 Evonik) was used as received. It has an average particle size of $30 \mathrm{~nm}$ and a BET specific surface area of $55 \mathrm{~m}^{2} / \mathrm{g}$. The anatase and rutile percentages were $70 \%$ and $30 \%$, respectively. RB5 solutions were prepared by dissolving the required quantity of dye in deionized water from a Millipore ${ }^{\circledR}$ purification system. Initial $\mathrm{pH}$ of the solution was monitored using a 209 pH meter from Hanna Instruments.

\subsection{UV-LEDs photoreactor}

The UV-LEDs selection was carried out aiming for a compromise between the price of each UV-LED, the $\mathrm{TiO}_{2}$ absorption spectra (Fig. 1A) and the LEDs power efficiency (Fig. 1B). LEDs with UV-C wavelength $(235-280 \mathrm{~nm})$ present a high cost $(€ / \mathrm{mW})$ and a reduced power efficiency (power emitted vs power consumed), compared to UV-A LEDs (Fig. 1B) [17]. Therefore, UV-A LEDs that present a reduced cost and a higher power efficiency were selected.

Experimental assays were carried out in a self-designed photoreactor. The photoreactor was composed of a matrix of 96 Indium Gallium Nitride (InGaN) UV-LEDs (Roithner RLSUV370E) with a maximum emission $\lambda=375 \mathrm{~nm}$ (UV-A) (Figs. $1 \mathrm{~A}$ and S2). The nominal consumption of each LED lamp is $80 \mathrm{~mW}$ operating at $20 \mathrm{~mA}$. Blue light is emitted (Figs. $1 \mathrm{~A}$ and S2) and the UV-A LEDs matrix has an illuminated area of $11 \times 7 \mathrm{~cm}^{2}$ and a total optical power emitted of approximately $100 \mathrm{~mW}$, depending on the root mean square (RMS) current intensity supplied. The system irradiance was measured using an UV enhanced Si-photodetector (ThorLabs PDA155) in a configuration that replicates the one used in the photoreactor. From the measured irradiance the photon flux delivered to the sample can be calculated and for the maximum value of irradiance, the 96 UV-A LEDs matrix presents a photon flux
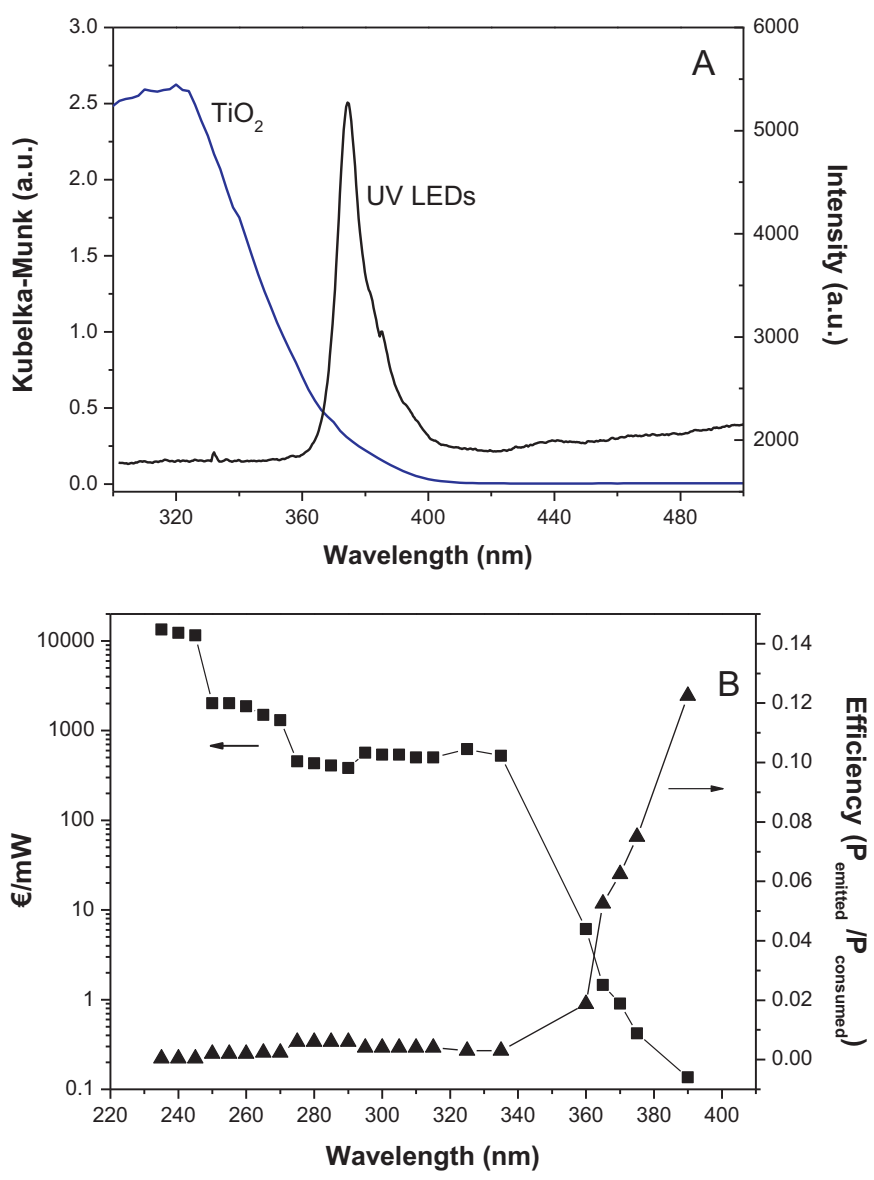

Fig. 1. UV-LEDs selection: (A) $\mathrm{TiO}_{2}$ absorption spectra and LEDs maximum emission wavelength ( $375 \mathrm{~nm})$; (B) $€ / \mathrm{mW}$ and LEDs power efficiency at different maximum emission wavelengths.

of $7.59 \times 10^{-7}$ Einstein/s. The output optical power is controlled using a pulse width modulation (PWM) circuit and the RMS current intensity was measured with a multimeter (UniVolt DT$64)$. Fig. S3 shows the UV-A LEDs irradiance $\left(I, \mathrm{~W} / \mathrm{m}^{2}\right)$ as function of current intensity ( $\mathrm{mA})$. The reactor was operated in a continuous flow-through mode. The UV-A LEDs photoreactor has a capacity of $100 \mathrm{~mL}$ and all its internal surfaces are formed by mirrors. The UVA LEDs matrix was fixed $5 \mathrm{~cm}$ above the $\mathrm{RB} 5 / \mathrm{TiO}_{2}$ mixture.

\subsection{Experimental procedure}

RB5 aqueous solutions were prepared in Milli- $Q^{\circledR}$ water with different concentrations $(25,50$ and $100 \mathrm{mg} / \mathrm{L})$. Then the desired amount of $\mathrm{TiO}_{2}$ was added $(0,0.25,0.5$ or $1.0 \mathrm{~g} / \mathrm{L})$ and an ultrasonic bath was used (Bandelin Sonorex SUPER PK 106) for 2 min to promote the catalyst dispersion in the suspension.

In a typical experiment, the suspension was loaded to the UV-A LED photoreactor through a peristaltic pump (Gilson Minipuls 3) with a specific flowrate. The photoreactor was fitted with a mixing unit and experiments were performed under well-mixing conditions. The $\mathrm{RB} 5 / \mathrm{TiO}_{2}$ suspension was equilibrated in the dark for $1 \mathrm{~h}$, before each experiment.

Irradiation of the suspensions started after the adsorption equilibrium between $\mathrm{TiO}_{2}$ and $\mathrm{RB} 5$ was achieved. The experiments were carried out at the natural $\mathrm{pH}$ of the solution suspension. The initial $\mathrm{pH}$ was $5.0 \pm 0.1$ in the experiments without $\mathrm{TiO}_{2}$, and $4.5 \pm 0.2$ in the experiments with $\mathrm{TiO}_{2}$. These values remained practically constant during the course of the reaction. Samples of the dye solution were withdrawn at periodic intervals during the 
course of the reaction, then analysed in a UV/vis Jasco V530 spectrophotometer (Tokyo, Japan) at $\lambda_{\max }=595 \mathrm{~nm}$.

The temperature was in the range of $21-22^{\circ} \mathrm{C}$. The concentration of RB5 in the bulk solution prior to irradiation was used as the initial value for the measurements of RB5 dye decolourization. At predetermined times, a $2 \mathrm{~mL}$ sample was withdrawn frm the irradiated suspension using a syringe. The catalyst was separated by centrifugation $(7500 \mathrm{rpm})$ from the aqueous solution prior to UV-vis analysis and the concentration of Reactive Black 5 in the solution was determined using a calibration curve of RB5 (concentration vs absorbance) prepared with known concentrations. All the experiments were carried out in duplicate and values presented are the average of both results. The observed standard deviation was always less than $5 \%$ of the reported value.

The concentration of residual RB5 was calculated by BeerLambert law, after dilution when necessary, using the optical density and the molar extinction coefficient observed at the characteristic wavelength and expressed as:

Dye decolourization $=\frac{1-C_{\text {dye }, t}}{C_{\text {dye }, t=0}} \times 100 \%$

where $C_{\mathrm{dye}, t}$ and $C_{\mathrm{dye}, t}=\mathrm{o}$ are the concentration of RB5 at reaction time $t$ and $0 \mathrm{~min}$, respectively.

\section{Results and discussion}

\subsection{Effect of $\mathrm{TiO}_{2}$ and $\mathrm{RB} 5$ concentration}

First, to study the effect of the amount of catalyst, the RB5 decolourization was evaluated with $\mathrm{TiO}_{2}$ absent (only UV-A LEDs photolysis). Colour disappearance was almost null. RB5 colour removal was then evaluated under a combination of $\mathrm{TiO}_{2}$ and UV-A LEDs. Fig. 2 shows the decolourization profile against irradiation time of RB5 solutions with: (A) different amounts of catalyst $\left(0,0.25,0.5\right.$ and $1.0 \mathrm{~g} / \mathrm{L}$ of $\left.\mathrm{TiO}_{2}\right)$ and (B) different dye concentrations $(25,50$ and $100 \mathrm{mg} / \mathrm{L}$ of RB5). This experiment revealed that the UV-A LEDs maximum wavelength $(\lambda=375 \mathrm{~nm})$ is unable to break the azo bonds $(-\mathrm{N}=\mathrm{N}-)$ which are responsible for the dye colour $(\lambda=595 \mathrm{~nm})$ and present in the RB5 structure (Fig. S1). However, using an irradiance of $40 \mathrm{~W} / \mathrm{m}^{2}$ and a flowrate of $1.5 \mathrm{~mL} / \mathrm{min}$, with $0.25,0.5$ and $1.0 \mathrm{~g} / \mathrm{L}$ of $\mathrm{TiO}_{2}, 22$, 41 and $64 \%$ of decolourization were reached, respectively. These results demonstrate that RB5 cannot be decolourized by UV-A LEDS photolysis alone and that, by increasing the catalyst amount up to $1.0 \mathrm{~g} / \mathrm{L}$, it is possible to increase the dye colour removal without any light scattering and/or screening effect which could affect the catalyst activity [10].

Fig. 2B shows the influence of dye concentration in the photocatalytic oxidation. The data obtained reveals that increasing the RB5 concentration diminishes the UV-A LEDs/TiO ${ }_{2}$ capacity to decolourize the aqueous solution. The highest decolourization was achieved with $25 \mathrm{mg} / \mathrm{L}$ (70\%) and the lowest with $100 \mathrm{mg} / \mathrm{L}$ of RB5 (only 15\%), for a flowrate of $1.5 \mathrm{~mL} / \mathrm{min}$. A possible explanation for this behaviour is that as the initial concentration of the dye increases, the path length of photons entering the solution decreases and in low concentration the reverse effect occurs, increasing the quantity of photon absorption by the catalyst in lower concentrations [18,19].

The RB5 decolourization achieved with the UV-A LEDs photocatalytic system can be tracked through the UV-vis spectra at different reaction times (Fig. 3). Before the photocatalytic treatment, the UV-vis spectra of RB5 consists of two main characteristic absorption bands. One in the UV region $\left(\lambda_{\max }=310\right.$ $\mathrm{nm})$ and another in the visible region $\left(\lambda_{\max }=595 \mathrm{~nm}\right)$. Significant changes are observed throughout the entire spectrum with
A)
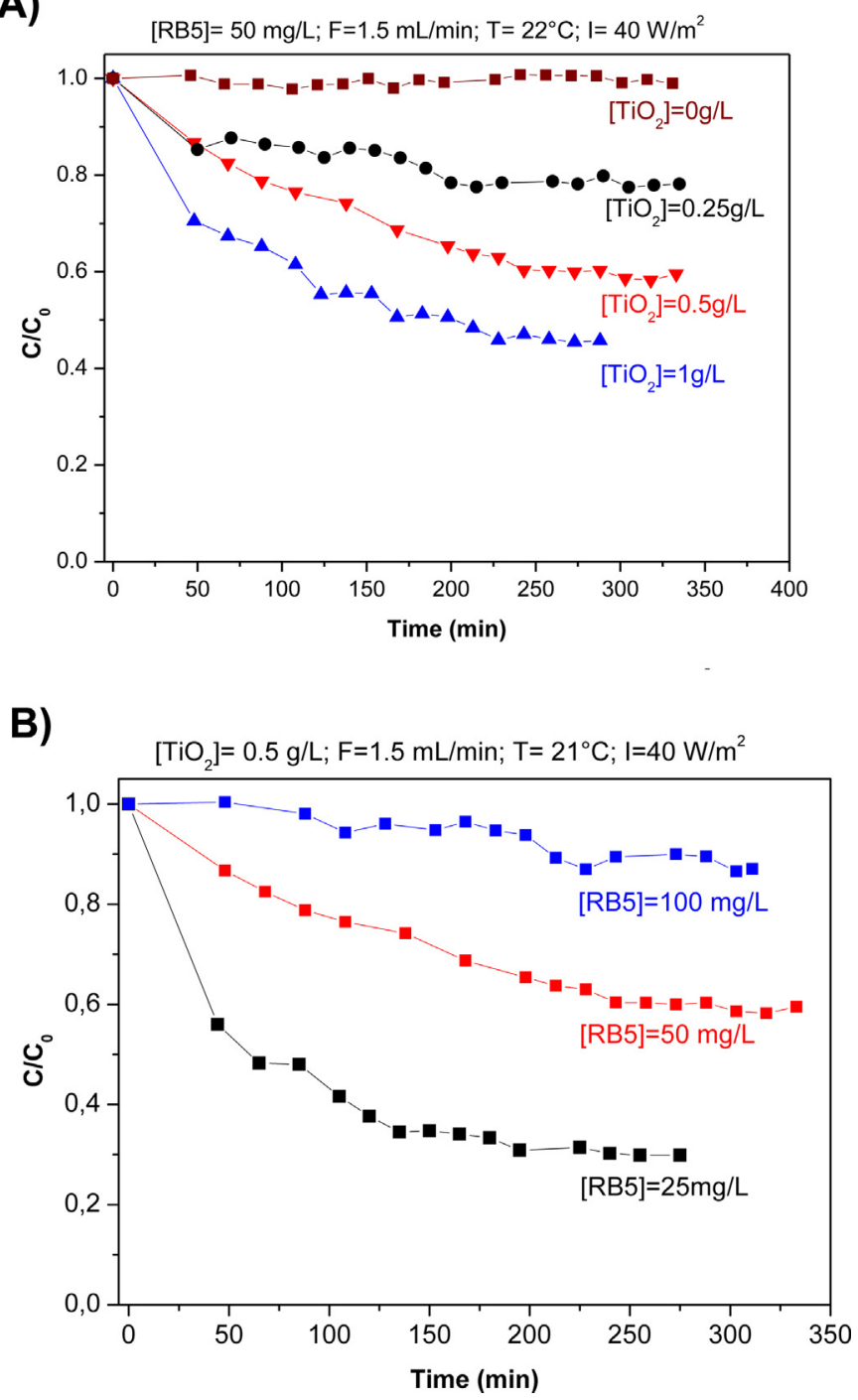

Fig. 2. Influence of $(A) \mathrm{TiO}_{2}$ and (B) dye concentration in the decolourization of RB5 solutions with the UV-A LEDs photoreactor.

time-especially at $\lambda_{\max }=595 \mathrm{~nm}$. The typical absorption band gradually diminishes as the reaction time increases, which suggests a significant photodegradation of RB5 by UV-A LEDs. The UV band at $\lambda_{\max }=310 \mathrm{~nm}$ also vanishes, but at lower rate. This UV band is characteristic of two adjacent aromatic rings, whereas the visible band $\left(\lambda_{\max }=595 \mathrm{~nm}\right)$ is due to a long conjugated $\pi$ system linked by two azo groups [20,21]. From UV-vis spectra it is possible to observe that the UV region between $\lambda=200$ and $350 \mathrm{~nm}$ shows higher absorption compared to the visible region. Therefore, decolourization occurs faster since it is easier to break the azo bond (opening the $\mathrm{N}=\mathrm{N}$ bonds) than the aromatic rings.

\subsection{Kinetics of RB5 decolourization}

To determine the kinetics of RB5 decolourization, the experimental results obtained were analysed using a continuous stirred tank reactor (CSTR) design equation in terms of kinetic investigation, further simplified to a pseudo-first order rate equation with respect to the dye concentration:

$\frac{\mathrm{d} N}{\mathrm{~d} t}=F_{0}-F+V \times r$ 
where $N$ number of moles in a reactor, $F_{0}$ is the inlet molar flowrate, $F$ is the outlet molar flowrate, $V$ is the reactor volume and $r$ is the reaction rate. This continuous stirred tank reactor system is steady state and the first term will be zero. Rearranging Eq. (1),

$V=\frac{F_{0}-F}{-r}$

$F_{0}=C_{0} \times v_{0}\left(v_{0}=\right.$ volumetric flow rate $)$

$F=C \times v_{0}$

Using these constants and rearranging Eq. (2),

$V=\frac{C_{0} \times v_{0} \times X}{-r}$

$-r=k \times C$ and $C=C_{0} \times(1-X)$

$-r=k \times C_{0} \times(1-X)$

Eq. (3) shows the kinetic details obtained from the experimental data.

In the continuous stirred tank reactor, the reacting mixture was well mixed so that the properties of the reacting mixture were uniformly distributed throughout the reactor and also to ensure the properties of the exit stream were the same as the reacting mixture within the reactor.

The influence of RB5 concentration, $\mathrm{TiO}_{2}$ dosage, flowrate and light irradiance in terms of kinetics is given in Table 1. Although increased concentration and flowrate negatively affect the reaction rate and reaction rate constants, the latter are positively affected by an increase in $\mathrm{TiO}_{2}$ amounts and light irradiances.

\subsection{Irradiance and flowrate influence}

Fig. 4 presents the photocatalytic oxidation of RB5 in the UVLEDs photoreactor under different water flowrates (from 0.8 to $2.2 \mathrm{~mL} / \mathrm{min}$ ) and UV irradiance (36, 40 and $46 \mathrm{~W} / \mathrm{m}^{2}$ ). These experiments were performed using a $50 \mathrm{mg} / \mathrm{L}$ RB5 solution and $1.0 \mathrm{~g} / \mathrm{L}$ of $\mathrm{TiO}_{2}$. From the data it is possible to observe that

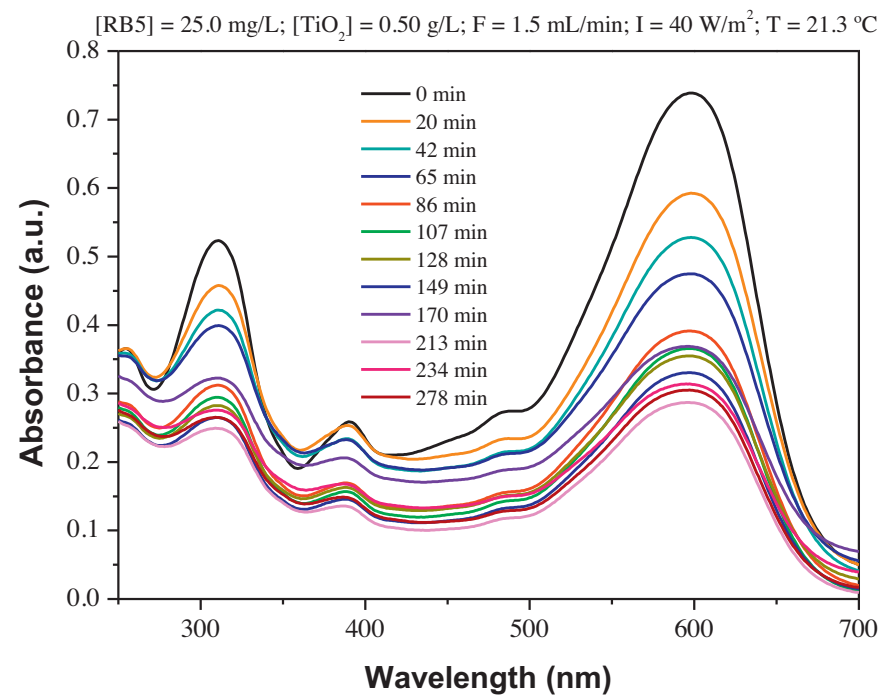

Fig. 3. Reactive Black 5 UV-vis spectra evolution along photocatalytic decolourization.
Table 1

Reaction rate and reaction rate constants calculated for different operational conditions.

\begin{tabular}{lcc}
\hline Experiments & $k\left(\mathrm{~min}^{-1}\right)$ & $r(\mathrm{~mol} / \mathrm{L} \mathrm{min})$ \\
\hline Effect of RB5 concentration $(\mathrm{mg} / \mathrm{L})(\mathrm{Fig} .2 \mathrm{~B})$ & \\
25 & $1.617 \times 10^{-2}$ & $1.957 \times 10^{-7}$ \\
50 & $3.277 \times 10^{-3}$ & $1.355 \times 10^{-7}$ \\
100 & $3.047 \times 10^{-4}$ & $3.011 \times 10^{-8}$ \\
& & \\
Effect of $\mathrm{TiO}_{2}$ amount (g/L) (Fig. $\left.2 \mathrm{~A}\right)$ & $9.031 \times 10^{-8}$ \\
0.25 & $2.035 \times 10^{-3}$ & $1.355 \times 10^{-7}$ \\
0.50 & $3.277 \times 10^{-3}$ & $2.483 \times 10^{-7}$ \\
1.0 & $7.351 \times 10^{-3}$ & \\
& & $3.227 \times 10^{-7}$ \\
Effect of flowrate $(\mathrm{mL} / \mathrm{min})($ Fig. 4$)$ & $1.881 \times 10^{-7}$ \\
0.8 & $3.211 \times 10^{-2}$ & $1.905 \times 10^{-7}$ \\
1.5 & $4.974 \times 10^{-3}$ & \\
2.2 & $4.552 \times 10^{-3}$ & \\
& & \\
Effect of irradiance $\left(\mathrm{W} / \mathrm{m}^{2}\right)($ Figs. $2 \mathrm{~A}$ and 4$)$ & $2.483 \times 10^{-7}$ \\
36 & $4.974 \times 10^{-3}$ \\
40 & $7.351 \times 10^{-3}$ & \\
\hline
\end{tabular}

RB5 decolourization is favoured by high irradiances, independently of the dye solution flowrate applied. However, this higher decolourization reveals a lower quantum yield of the system. In a chemical photodegradation process, when a molecule decomposes after absorbing a light quantum, the quantum yield is the number of destroyed molecules divided by the number of photons

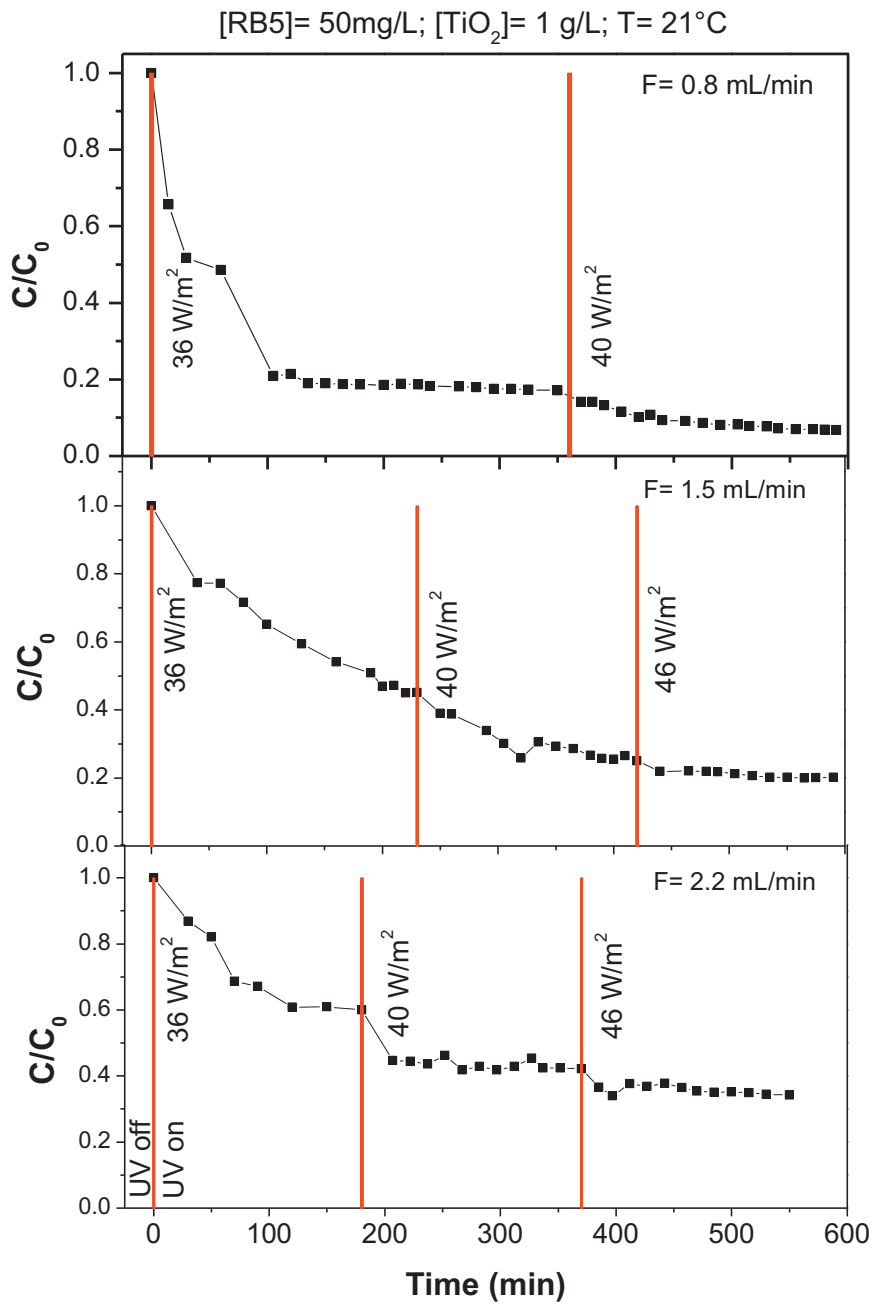

Fig. 4. Influence of irradiance $(I)$ and solution flowrate $(F)$ on RB5 decolourization. 
absorbed by the system. In photocatalysis the quantum yield $(\Phi)$ can be defined as the ratio of moles of reactant consumed, or product formed, in the bulk phase per Einstein absorbed by the photocatalyst, according to Eq. (4) [22]:

$\Phi_{\text {photodegradation }}=\frac{k}{2.303 \times I_{\lambda} \times \varepsilon_{\lambda} \times l}$

where $\Phi_{\text {photodegradation }}$ is the photodegradation quantum yield, $k$ $\left(\mathrm{s}^{-1}\right)$ is the pseudo first order rate constant, $I_{\lambda}$ (Einstein $\mathrm{L}^{-1} \mathrm{~s}^{-1}$ ) is the light intensity at wavelength $\lambda, \varepsilon_{\lambda}\left(\mathrm{cm}^{-1} \mathrm{~mol} \mathrm{dm}^{-3}\right)$ is the molar absorptivity at wavelength $\lambda$, and $l$ is the cell path length $(\mathrm{cm})$.

Regarding the above mentioned equation it is easily verified that an increase in the light intensity $\left(I_{\lambda}\right)$ will decrease the quantum yield of the photocatalytic process. Thus, high UV intensities rise the number of molecules destroyed but the yield is inferior, since the number of photons applied is significantly higher.

Among the factors taken into account in selecting a method for the degradation of pollutants, one of the most important is economic. Photodegradation of pollutants in aqueous solution is an energy demanding process, electric energy being the major factor of operating cost. The electrical energy efficiency $\left(E_{\mathrm{EO}}\right)$ is the electric energy in kilowatt hours $(\mathrm{kWh})$ required to degrade a contaminant by one order of magnitude in a unit volume of contaminated water. $E_{\mathrm{EO}}\left(\mathrm{kWh} / \mathrm{m}^{3} /\right.$ order $)$ can be calculated according to the following Eq. (5) [23]:

$E_{\mathrm{EO}}=\frac{P}{F \times \log \left(C_{\mathrm{i}} / C_{\mathrm{f}}\right)}$

where $P$ is the electric power consumed by the lamp $(\mathrm{kW}), F$ is the dye solution flowrate $\left(\mathrm{m}^{3} / \mathrm{h}\right), C_{\mathrm{i}}$ and $C_{\mathrm{f}}$ are the initial and final concentrations of the RB5 dye.

Fig. 5 shows that the cheapest UV-A LEDs/ $/ \mathrm{TiO}_{2}$ treatment is achieved with low flowrates and high electric power. The figure-ofmerit $E_{\mathrm{EO}}$ reaches values of about $220 \mathrm{kWh} / \mathrm{m}^{3} /$ order, clearly below that obtained with other UV LEDs, Table 2 [24], for an electric power consumption of $0.0129 \mathrm{~kW}$ and a solution flowrate of $4.8 \times 10^{-6} \mathrm{~m}^{3} / \mathrm{h}$. Based on the data obtained with an electric power consumption of $0.0142 \mathrm{~kW}$ and wastewater flowrate of $9.0 \times 10^{-6} \mathrm{~m}^{3} / \mathrm{h}$, it is possible to surmise that a value nearer to $200 \mathrm{kWh} / \mathrm{m}^{3} /$ order could be achieved. It is worth highlighting that electrical efficiency is higher for the photocatalytic process

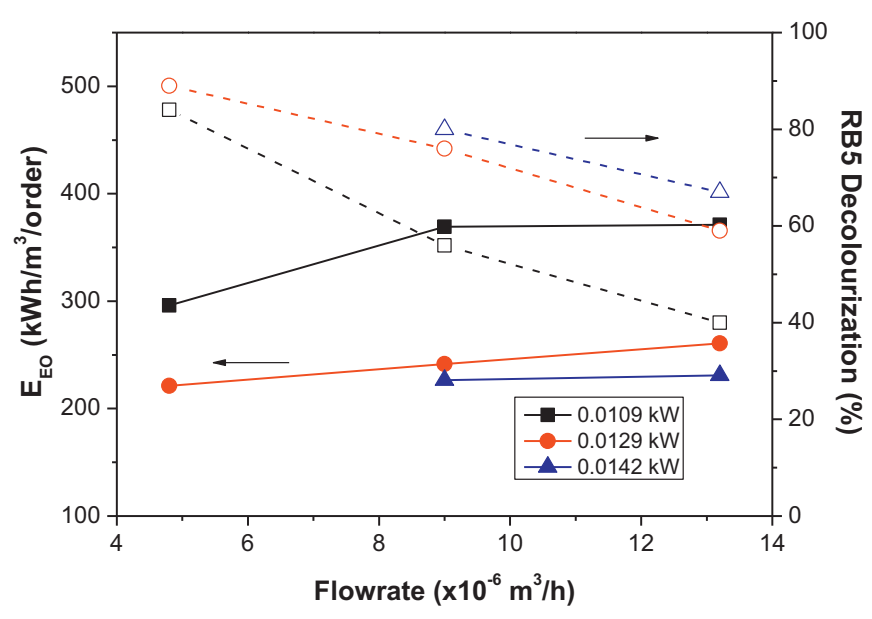

Fig. 5. Power (kW) and wastewater flowrate influence on RB5 decolourization and electric energy per order $\left(E_{\mathrm{EO}}\right)$.
Table 2

Kinetic constants and $E_{\mathrm{EO}}$ values obtained in continuous dye degradation with UV LEDs/ $/ \mathrm{TiO}_{2}[24]$.

\begin{tabular}{lcc}
\hline Dye & $k\left(\mathrm{~min}^{-1}\right)$ & $E_{\mathrm{EO}}\left(\mathrm{kWh} / \mathrm{m}^{3} /\right.$ order $)$ \\
\hline Malachite green & $3.8 \times 10^{-3}$ & 789.47 \\
Methylene blue & $1.0 \times 10^{-3}$ & 3000 \\
Rhodamine B & $2.0 \times 10^{-3}$ & 1500 \\
\hline
\end{tabular}

compared to the photolytic process (Fig. $2 \mathrm{~A}, 0 \mathrm{~g} / \mathrm{L} \mathrm{TiO}_{2}$ ). The UVA LEDs photolytic process, with the almost null decolourization of the dye, attains an $E_{\mathrm{EO}}$ value of $32,838 \mathrm{kWh} / \mathrm{m}^{3} /$ order. This shows the extreme importance of $\mathrm{TiO}_{2}$ in the decolourization process. Despite the small overlapping of the $\mathrm{TiO}_{2}$ absorption curve with the UV-A LEDs maximum emission wavelength (Fig. 1A), this is the key to promoting the generation of $\mathrm{HO}$, and therefore, promoting RB5 oxidation.

\section{Conclusions}

As a potential alternative to conventional treatments, the photocatalytic oxidation of a textile dye in a continuous stirred tank reactor with UV-A LEDs/ $/ \mathrm{TiO}_{2}$ was revealed to be an efficient treatment process. An RB5 decolourization of $89 \%$ was achieved using an irradiance of $40 \mathrm{~W} / \mathrm{m}^{2}, 1.0 \mathrm{~g} / \mathrm{L}$ of $\mathrm{TiO}_{2}, 50 \mathrm{mg} / \mathrm{L}$ of RB5 and a wastewater flowrate of $0.8 \mathrm{~mL} / \mathrm{min}$. In addition, the figure-of-merit electrical energy per order $\left(E_{\mathrm{EO}}\right)$ was obtained for the photoreactor and values of around $200 \mathrm{kWh} / \mathrm{m}^{3} /$ order were attained.

From the above, it can be seen that UV-A LEDs photocatalysis could be an excellent way to reduce the high cost of UV-driven advanced oxidation processes and make them viable to industrial wastewater treatment plants.

Furthermore, different operational conditions, such as catalyst variation (e.g. $\mathrm{N}-\mathrm{TiO}_{2}, \mathrm{CNT}-\mathrm{TiO}_{2}$, graphene-TiO ${ }_{2}$ ), UV-A LEDs maximum emission wavelength, temperature, $\mathrm{pH}$ and hydrogen peroxide addition, could be explored in future research.

\section{Acknowledgements}

The authors are grateful to Fundação para a Ciência e a Tecnologia (FCT) for the financial support provided to CQVR (PestOE/QUI/UI0616/2014). Marco S. Lucas acknowledges also the funding provided by the European Union's Horizon 2020 research and innovation programme under the Marie Sklodowska-Curie grant agreement No. 660969.

\section{Appendix A. Supplementary data}

Supplementary data associated with this article can be found, in the online version, at http://dx.doi.org/10.1016/j.jece.2015.10.042.

\section{References}

[1] P.R. Gogate, A.B. Pandit, A review of imperative technologies for wastewater treatment I: oxidation technologies at ambient conditions, Adv. Environ. Res. 8 (2004) 501-551.

[2] C.M. Teh, A.R. Mohamed, Roles of titanium dioxide and ion-doped titanium dioxide on photocatalytic degradation of organic pollutants (phenolic compounds and dyes) in aqueous solutions: a review, J. Alloys Compd. 509 (2011) 1648-1660.

[3] W.H. Glaze, J.W. Kang, D.H. Chapin, The chemistry of water treatment processes involving ozone, hydrogen peroxide and ultraviolet radiation, Ozone Sci. Eng. 9 (1987) 335-342.

[4] R. Andreozzi, V. Caprio, A. Insola, R. Marotta, Advanced oxidation processes (AOP) for water purification and recovery, Catal. Today 53 (1999) 51-59.

[5] S. Malato, J. Blanco, A. Vidal, C. Richter, Photocatalysis with solar energy at pilot-plant scale: an overview, Appl. Catal. B Environ. 37 (2002) 1-15. 
[6] M.S. Lucas, R. Mosteo, M.I. Maldonado, S. Malato, J.A. Peres, Solar photochemical treatment of winery wastewater in a CPC reactor, J. Agric. Food Chem. 57 (2009) 11242-11248.

[7] M.R. Hoffmann, S.T. Martin, W. Choi, D.W. Bahnemann, Environmental applications of semiconductor photocatalysis, Chem. Rev. 95 (1995) 69-96.

[8] M. Litter, Heterogeneous photocatalysis: transition metal ions in photocatalytic systems, Appl. Catal. B Environ. 23 (1999) 89-114.

[9] A. Zielinska-Jurek, E. Kowalska, J.W. Sobczak, W. Lisowski, B. Ohtani, A. Zaleska, Preparation and characterization of monometallic (Au) and bimetallic ( $\mathrm{Ag} / \mathrm{Au})$ modified-titania photocatalysts activated by visible light, Appl. Catal. B Environ. 101 (2011) 504-514.

[10] R.J. Tayade, T.S. Natarajan, H.C. Bajaj, Photocatalytic degradation of methylene blue dye using ultraviolet light emitting diodes, Ind. Eng. Chem. Res. 48 (2009) 10262-10267.

[11] M.A. Würtele, T. Kolbe, M. Lipsz, A. Külberg, M. Weyers, M. Kneissl, M. Jekel, Application of GaN-based ultraviolet-C light emitting diodes-UV LEDs-for water disinfection, Water Res. 45 (2011) 1481-1489.

[12] I. Carra, J.A.S. Pérez, S. Malato, O. Autin, B. Jefferson, P. Jarvis, Application of high intensity UVC-LED for the removal of acetamiprid with the photo-Fenton process, Chem. Eng. J. 264 (2015) 690-696.

[13] S.H. Vilhunen, M.E.T. Sillanpää, Ultraviolet light emitting diodes and hydrogen peroxide in the photodegradation of aqueous phenol, J. Hazard. Mater. 161 (2009) 1530-1534.

[14] Z. Wang, J. Liu, Y. Dai, W. Dong, S. Zhang, J. Chen, CFD modelling of a UV-LED photocatalytic odor abatement process in a continuous reactor, J. Hazard. Mater. 215-216 (215) (2012) 25--.
[15] M.H. Crawford, M.A. Banas, M.P. Ross, D.S. Ruby, J.S. Nelson, R. Boucher, A.A. Allerman, Final LRDR report: ultraviolet water purification systems for rural environments and mobile applications, Sandia Rep. (2005) .

[16] W.-Y. Wang, Y. Ku, Photocatalytic degradation of Reactive Red 22 in aqueous solution by UV-LED radiation, Water Res. 40 (2006) 2249-2258.

[17] http://www.roithner-laser.com/ (accessed 12.11.14).

[18] R.J. Davis, J.L. Gainer, G.O. Neal, I. Wenwu, Photocatalytic decolorization of wastewater dyes, Water Environ. Res. 66 (1994) 50-53.

[19] R.W. Matthews, Photocatalytic oxidation and adsorption of methylene blue on thin films of near-ultraviolet-illuminated $\mathrm{TiO}_{2}$, J. Chem. Soc. Faraday Trans. 85 (1989) 1291-1302.

[20] R.M.C. Silverstein, G.C. Bassler, G.C. Morrill, Spectrometric Identification of Organic Compounds, Wiley, New York, 1991.

[21] M.S. Lucas, J.A. Peres, Decolorization of the azo dye Reactive Black 5 by Fenton and photo-Fenton oxidation, Dyes Pigm. 71 (2006) 235-243.

[22] C. Martínez, S. Vilariño, M.I. Fernández, J. Faria, M.L. Canle, J.A. Santaballa, Mechanism of degradation of ketoprofen by heterogeneous photocatalysis in aqueous solution, Appl. Catal. B 142-143 (2013) 633-646.

[23] J.R. Bolton, K.G. Bircher, W. Tumas, C.A. Tolman, Figure-of-merit for the technical development and application of advanced oxidation technologies for both electric and solar driven systems (IUPAC Technical Report), Pure Appl. Chem. 73 (2001) 627-637.

[24] K. Natarajan, T.S. Natarajan, H.C. Bajaj, R.J. Tayade, Photocatalytic reactor based on UV-LED $/ \mathrm{TiO}_{2}$ coated quartz tube for degradation of dyes, Chem. Eng. J. 178 (2011) 40-49. 